\title{
NATURALEZA Y SOCIEDAD: \\ LA REFORMULACION ACTUAL DE UN VIEJO DEBATE
}

La historia de este número monográfico de «Papers» arranca de una preocupación por el impacto que sobre las ciencias humanas está causando la pujanza teórica de la biología en sus diversas ramas. Es una influencia no fácil de valorar, por lo menos en cuanto a sus consecuencias a medio plazo. Sea cual fuere la historia de la relación entre las ciencias sociales y las ciencias de la vida ( $\mathrm{y}$ en las páginas de este númeto afloran numerosos episodios que la ilustran), la coyuntura actual se caracteriza porque los biólogos se han arrogado el derecho de dar explicaciones desde su terreno a cuestiones que convencionalmente estaban reservadas a sociólogos, psicólogos y antropólogos. Los científicos sociales no se cierran en banda ante una honesta tentativa de simbiosis entre campos del saber. Ya hace tiempo que la biología tiene zonas comunes, pacíficamente compartidas, con la . psicología y la antropología (neurobiología, psicofisiología, genética y comportamiento, antropología física...) Lo que les ha irritado profundamente (y también inquietado) es la actitud de algunos biólogos, sobre todo aquellos que desfilan tras los estandattes de Ia sociobiología. La teacción de muchos científicos sociales ha sido la de quien repele la «invasión de los bárbaros». Dejando aparte invectivas y argumentaciones, más viscerales que tacionales, la gran generalidad ha aceptado el desafío. Un primer resultado 
a corto plazo ha sido someter a revisión y a discusión muchos conceptos de las ciencias humanas para filtrat hasta donde les afectan las pretensiones explicativas de la biología. Creemos que, desde este ángulo, el trabajo de depuración y de demarcación ha sido ingente y fructífero. Los científicos sociales han contado además con la valiosa ayuda de los filósofos. Frente a las tradiciones durkheimiana y watsoniana, tepletas de ramalazos antiespiritualistas, son ellos quienes nos hablan sin pudor de sentimientos, intenciones, conciencia, conceptos que los biólogos no necesitan para explicar el comportamiento animal y que nosotros sí necesitamos para explicar enteramente el comportamiento humano. A fuerza de pregonar la sobriedad ex. plicatoria mucho es de temer que les hayamos puesto a los biólogos las cosas «en bandeja».

Pese a todo esto, estamos lejos de sugerir que la biología no tenga absolutamente nada que decir en el dominio de las ciencias humanas. EI corazón del debate es, en estos momentos, discernir qué puede aportar la biología a un mejor conocimiento del hombre. Las circunstancias han hecho que Ia iniciativa haya partido de los biólogos. ¿Habrían ido por otro camino las cosas si el primer paso lo hubieran dado los científicos sociales? Es difícil imaginarlo. Si impertinente es el afán conquistador de unos cuantos biólogos pertrechados de su reduccionismo, no menos ingenuo ha sido el proteccionismo de los científicos sociales que siguen la letra el aforismo durkheimiano de los hechos sociales por los hechos sociales. Con estas premisas mucho habrá que forzar los conjuros que nos pongan al alcance la tan soñada interdisciplinatidad.

Al planear este número convinimos desde el primer momento en evitar la «fijación» en el tema crispante de la sociobiología. Bien es verdad que los sociólogos se sienter proclives a ajustar cuentas con ella, tanto por sus implicaciones ideológicas como por la no disimulada insolencia con que trata a la sociología. Sin embargo, optamos por dat un tono más «ecuménico» a nuestra empresa y presentar un panorama sobre biología y ciencias humanas en el que se analizan las interferencias de la primera con la sociología, la psicología y la antropología. Esto nos daría pie a fundamentar mejor la crítica de la irrupción de la biología en nuestros dominios. El attículo con que se abre este número responde a estas intenciones. En él ofrecemos, en frontispicio, una exposición sucinta y bastante completa del paradigma de Darwin en su versión actual. El evolucionismo está convirtiéndose en la espina dorsal de la biología en este final del siglo xx. Creemos que para penetrat en el meollo del tema de la aproximación entre biología y ciencias humanas es preciso entender el alcance y los límites de las proposiciones y corolarios de la teoría de la evolución de las especies que coloca en su ápice al Homo Sapiens. Junto a Darwin está Mendel: la 
genética es otra de las piezas que cierran el arco de la bóveda que se tiende desde la biología a las ciencias sociales. En el mismo artículo pasamos una rápida revista a las aportaciones que la etología, la sociobiología, y la ecología hacen, indistintamente, a la psicología, la sociología y la antropología.

La segunda parte del número la constituyen cuatro artículos monográficos. En el primero, D. Greenwood, catedrático de Biología y Sociedad de Ia universidad de Cornell, hace una fina crítica de ese mito del «eterno tetorno" que protagoniza el empeño biológico por fundamentat las ciencias del comportamiento en una noción de «natutaleza bumana» extraída de sus indagaciones científicas. Seguidamente Sactamento Martí y Angel Pes. taña, historiadora la primera e investigador en biología molecular el segundo, someten a una crítica implacable algunos de los conceptos biológicos que podrían servir de piezas justificativas de un orden social que vincula el status de la mujer a su función reproductora, Ramon Vaidés, profesor agregado de Antropología de la $\mathrm{UAB}$, nos ofrece un ameno, al par que incisivo, análisis de la mutua influencia entre la ecología de los grupos humanos primitivos, su tecnología y la evolución cultural. Su artículo sintetiza muy bien las inquietudes que orientan la moderna antropología ecológica. Juan Martínez Alier, catedrático de Ciencias Económicas de la $U A B$, nos ofrece un análisis de la relación entre economía y fuentes de energía. La idea que sobrevuela sus refiexiones es que la teoría económica es, por sí sola, incapaz de definir pautas que rïjan la explotación de los bienes escasos únicamente en función de un sistema de precios; es preciso introducir además un sistema de valores éticos.

La tercera parte se extiende en una serie de comentarios de libros sobre el tema monográfico que nos ocupa. No es un meto apéndice ilustrativo y menos aún de crítica literaria. El lector podrá comprobar allí que el prudente distanciamiento que los «editores» del número hemos mantenido en el artículo de fondo se trueca, a tatos, en claras tomas de posición ante las nuevas formas de reduccionismo, particularmente el sociobiológico.

Una de las mayores dificultades que afronta un trabajo de esta índole es la de encontrar la expresión justa que haga accesible a los científicos sociales el hilo de argumentación que trenzan los biólogos. No estamos se. guros de haber salido del todo airosos en la empresa. Es el dilema de quien se dirige a un público culto, universitatio incluso, pero con formación básica diversa. Estamos convencidos, con todo, que una discusión seria desde las ciencias sociales sobre, por ejemplo, las proposiciones sociobiológicas exige un conocimiento no trivial de la biología, en particular de la biología de poblaciones. Muchos científicos sociales atacan a la sociobiología por simplificar y banalizar la enorme complejidad de la interacción 
humana y social. Tienen razón. Pero no hacen excesivo esfuerzo por entrar en el modo de tazonamiento biológico, con lo cual los sociobiólogos tienen también razón al acusarles de tergiversar sus ideas. Es así que hemos llegado a un diálogo de sordos. Por supuesto, no nos corresponde aquí suplir las lagunas de formación en biología elemental de más de un lector. Eso es una tatea de bachillerato y también de una universidad menos crispada en unos progtamas burocráticamente canalizados hacia campos del saber tan mal delimitados como bien defendidos.

Para terminar, queremos dejar constancia de que nos hubiera encantado iniciar aquí una prolongada lista de agradecimientos. Cuando, en revistas extranjeras, leemos artículos de calidad diversa que con frecuencia han sido escritos bajo los auspicios de una institución con una sigla de varias mayúsculas; con un «grant» o contrato identificable por más mayúsculas y cuatro o seis números, se nos pone la cara de envidia por razones obvias. Lamentamos no poder citar a ninguna institución por haber financiado este proyecto. En todo caso, sí que habría que agradecer la preparación remota del mismo a las instituciones que nos becaron con un afio de estancia en USA (1977 A. Pexinat y $1980 \mathrm{~L}$. Lemkow), donde se perfilaron nuestros intereses en el tema de biología y ciencias humanas. Estas instituciones son: la Comisión de Intercambio Cultural España-USA y la Fundació del Congrés de Cultura Catalana. Aparte las horas que haya podido contabilizar este trabajo, el capítulo de gastos más fuerte ha sido el de los libros. Nuestras bibliotecas universitarias son una desolación. La petición de libros, si el presupuesto las cubre, puede alargarse un año. El postrer recurso es encargarlos a título personal.

Este trabajo, pese a las dificultades y carencias que hemos padecido en su confección, ha sido sumamente placentero. Muchos amigos universitatios a quienes hemos hecho partícipes de nuestro proyecto nos han animado a realizarlo. Les estamos agradecidos por su apoyo moral. Igualmente a los colegas del departamento de Sociología que, además de depositar en nosotros su confianza, han contribuido con sus opiniones a perfilar las líneas generales de este proyecto. Agradecemos a la Biblioteca general de la UAB en la persona de su secretaria general, la señorita Pilar Palau, el habernos conseguido un libro en un tiempo récord. $Y$, por supuesto, agradecennos a todos los que han accedido a dedicar su tiempo y su pluma para que este número de «Papers» fuera una aportación digna y esclarecedora al tema de Biología y Ciencias Humanas.

Adolfo Perinat

LOUIS LEMKOW

Bellaterra, 30 septiembre 1982 